\title{
A tormenta de um crowdfunding de jogo brasileiro
}

\author{
Cristiano Max Pereira Pinheiro, Eduardo Muller e Mauricio Barth
}

\section{Resumo}

Os modelos de financiamento e fomento para projetos de jogos no Brasil estão sendo aprofundados e aplicados de forma a percebermos como o processo de produção se ajusta à gestão de projetos e à captação de recursos. Este artigo resgata o processo de planejamento e execução da campanha de crowdfunding do jogo "Tormenta - os Desafios dos Deuses", realizado entre a Universidade Feevale de Novo Hamburgo, no Rio Grande do Sul, e a Jambô Editora, detentora da propriedade intelectual do sistema de RPG Tormenta. Esse projeto arrecadou a maior verba de jogo digital brasileiro até o momento, mais de $\mathrm{R} \$ 70.000$, em um sistema de Crowdfunding Nacional. A análise considera a natureza dos projetos em Economia Criativa, o processo de Campanha de Comunicação e as métricas alcançadas nos momentos das realizações das ações.

\section{Palavras-Chave}

Indústria Criativa. Modelos de Negócios.

Jogos Digitais.

\section{Cristiano Max Pereira Pinheiro}

I maxrs@feevale.br Doutorado em Comunicação Social pela PUCRS; coordenador dos Cursos de Jornalismo, Relações Públicas e Publicidade e Propaganda e professor do Mestrado em Indústria Criativa da Universidade Feevale.

Eduardo Muller I eduardomuller@feevale.br Mestrado em Comunicação Social pela PUCRS; professor no Curso de Jogos Digitais da Universidade Feevale.

Mauricio Barth I mauricio@feevale.br Mestrado em Indústria Criativa pela Universidade Feevale; professor no Curso de Publicidade da Universidade Feevale.

\section{Introdução}

Este artigo é parte de um trabalho de registro, documentação e construção de ciência a partir do caso do jogo Tormenta ${ }^{1}$. A proposta neste ensaio é relatar as etapas executadas pela equipe responsável pelo projeto Tormenta na Universidade Feevale, em parceria com a Jambô Editora. Alia-se a isso uma análise teórica sobre 0 crowdfunding como modelo de negócio alternativo para os projetos de jogos digitais no Brasil.

While scholars identify a range of social, cultural, economic, political and technological factors that suggest the need for a (re)consideration of videogames by students of media, culture and technology, here, it is useful to briefly examine just three reasons why videogames demand to be treated seriously: the size of videogame industry; the popularity of videogames; videogames as an example of human-computer interaction. ${ }^{2}$

Os jogos digitais aceleraram sua reputação de negócio sério ao longo dos últimos 20 anos.

Como afirma Newman (2004), não se podem desconsiderar os jogos digitais, dados o tamanho financeiro da indústria e a popularidade enquanto linguagem, a qual, por sua vez, apresenta um 
formato encantador e em constante inovação na relação homem-máquina.

A indústria dos jogos digitais está sendo encarada como promissora em diversos países devido aos constantes relatórios apresentados de taxa de crescimento anual (NEWZ00, 2014). No Brasil, a indústria passa por uma nova etapa de amadurecimento, consolidando associações, articulações políticas, pesquisas de mercado e formação acadêmica.

Neste cenário de desenvolvimento, surgem problemas e oportunidades; neste caso, tratase da experiência de financiar um projeto de desenvolvimento em um crowdfunding.

\section{Crowdfunding}

A busca por um formato de viabilidade para um projeto de jogos digitais esbarra na dualidade entre adquirir um passivo no formato de financiamento e um fomento, geralmente, governamental, que não onere de forma fixa a estrutura de custos do projeto. 0 financiamento pode ser oriundo de uma instituição bancária ou de amigos e familiares (GORDON, 2009).

Os tipos de modelos de negócios historicamente utilizados para projetos de jogos digitais não são o foco deste ensaio e já foram abordados extensivamente em outros trabalhos ${ }^{3}$ de base. Nesse sentido, será resgatada teoricamente apenas a fundamentação do modelo de Crowdfunding para este ensaio.

0 crowdfunding ou, em uma livre tradução, financiamento de grupo é uma modalidade de arrecadação de recursos de pessoas físicas que, através de um serviço, neste caso, por um sistema de internet, repassam valores por boleto bancário, depósito ou cartões de débito e crédito para o prestador de serviço deste sistema, que, ao final de um período de exposição do projeto, se alcançada a meta previamente estabelecida, repassa esse valor ao proponente do projeto, retirando sua margem de administração. Caso o projeto não alcance a meta estabelecida com limite mínimo para execução do projeto, os valores empenhados pelas pessoas físicas são devolvidos sem nenhum ônus.

Simple put, crowdfunding is the process of asking the general public for donations that provide startup capital for new ventures. Using the technique, entrepreneurs and small business owners can bypass venture capitalists and angel investors entirely and instead pitch ideas

Disponível em: <http://catarse.me/pt/tormentadesafio>. Acesso em: 01 mai. 2014.

Tradução do trecho pelos autores: "Enquanto estudiosos identificam o alcance social, cultural, econômico, político e os fatores tecnológicos que sugerem uma (re)consideração dos videogames pelos estudantes das mídias, cultura e tecnologia; aqui, é útil examinar apenas três razões pelas quais os videogames se tornaram uma demanda a ser tratada seriamente: 0 tamanho da indústria de videogames; a popularidade dos videogames; e os videogames como um exemplo de interação homem-máquina" (NEWMAN, 2004).

Tese de Doutorado do Autor: Cristiano Max - Apontamentos para uma aproximação entre jogos digitais e comunicação. Disponível em: <http://bdtd.ibict.br/>. Acesso em: 01 mai. 2014. 
straight to everyday Internet users, who provide financial backing. ${ }^{4}$

Esse modelo de financiamento de projeto é interessante para jogos digitais, não apenas porque provê o recurso financeiro, mas também porque é uma oportunidade para testar o produto e seu engajamento com o futuro público de consumo. A relação das pessoas que financiam o projeto ocorre, normalmente, por uma contrapartida relacionada com a doação. 0 doador, dependendo do valor, recebe um vale-cópia do jogo, seu nome nos créditos, um personagem com sua imagem e assim variam as contrapartidas. Essa relação é parte do contrato informal de relação entre 0 produto e 0 financiador físico pessoal, fazendo, dessa maneira, com que o mesmo se sinta parte do projeto, e não apenas uma compra antecipada.

São diversos os casos de jogos digitais em sistemas de crowdfunding no exterior que aparecem nas publicações específicas de jogos digitais. 0 Project Eternity é um desses exemplos, tendo arrecadado US\$ 3.986.929,00 em 2012. Em uma lista de consolidação constante no site Wikipedia ${ }^{5}$, pode-se contabilizar pelo menos 13 jogos que ultrapassaram a barreira de US $\$ 1.000 .000,00$ de arrecadação, e grande parte das iniciativas entre US $\$ 100.000,00$ e US $\$ 500.000,00$. Isso demonstra que existe viabilidade latente para o financiamento/ fomento de iniciativa de projetos de jogos digitais neste tipo de sistema. "Perhaps the greatest impact of the creative economy is not only within the traditional creative industries but in the way their skills and business models are being used to create value in other areas of life." 6

0s jogos digitais, assim como outros produtos dos setores criativos, têm experimentado novos formatos de modelos de negócio para viabilizar os tipos de projetos e as necessidades de cada formato de empresa que o mercado está estabelecendo. A proposta que se apresenta no Projeto Tormenta não é inovadora, de fato, é a apropriação do uso de outros projetos de jogos, como apresentado anteriormente, e adaptado a uma realidade nacional.

\section{Projeto Tormenta}

0 Projeto Tormenta se caracteriza pela produção de um jogo do Universo Ficcional Tormenta, criado

Tradução do trecho pelo autor: "De forma simples, crowdfunding é o processo de pedir ao público por doações para prover um capital inicial para novos projetos. Usando essa técnica, os empreendedores e donos de pequenos negócios podem evitar os capitais de risco e os investidores anjos e apresentar todo dia ideias diretamente aos usuários de internet, que irão prover 0 financiamento" (STEINBERG; DEMARIA, 2012).

Disponível em: <http://goo.gl/WZxAG3>. Acesso em: 01 mai. 2014.

Tradução do trecho pelo autor: "Talvez o grande impacto da Economia Criativa não seja apenas na tradicional indústria criativa, mas na maneira como suas habilidades e modelos de negócios estão sendo usados para criar valor em outras áreas da vida” (HOWKINS, 2005). 
em 2000 por Marcelo Cassaro, J. M. Trevisan e Rogerio Saladino, e que, atualmente, é uma $\mathrm{PI}^{7}$ da Jambô Editora, sendo editada hoje em dia por Guilherme Dei Svaldi, Leonel Caldela e Gustavo Brauner. Neste tópico, iremos apresentar 0 registro dos acontecimentos que desencadeiam 0 projeto, seu planejamento, a criação da demo, a campanha e 0 registro destes fatos.

No início de julho de 2012, a Editora apresentou à Universidade Feevale a ideia de uma produção independente com uso de sua PI, porém sem recursos financeiros para o projeto, ou seja, a Editora procurava por uma oportunidade. No retorno das atividades do segundo semestre, em agosto de 2012, foi apresentada uma alternativa à Editora. A produção de uma demonstração do jogo que fosse utilizada para buscar recursos em plataformas de crowdfunding. Segundo Steinberg e DeMaria (2012), uma das boas oportunidades para proposição de um modelo de negócios baseado em crowdfunding é quando se possui uma PI que seja reconhecida por uma base de fãs. Essa demonstração contaria com uma parte de cenário e a utilização de um personagem, além dos inimigos. Pela estrutura apresentada para a produção, essa demonstração era caracterizada mais como uma prototipagem bem finalizada do que uma demonstração de jogo. Esse protótipo seria utilizado para produzir 0 vídeo para campanha e as imagens de publicidade do projeto.

Era importante frisar no desenvolvimento do protótipo, tanto para a Editora quanto para 0 público da campanha de arrecadação, que a versão apresentada do jogo era apenas uma prototipagem. Trabalhou-se com a execução de um protótipo que pudesse estabelecer o clima gráfico do universo; o prazo de desenvolvimento não iria

Figura 1: Screenshot do Jogo Tormenta

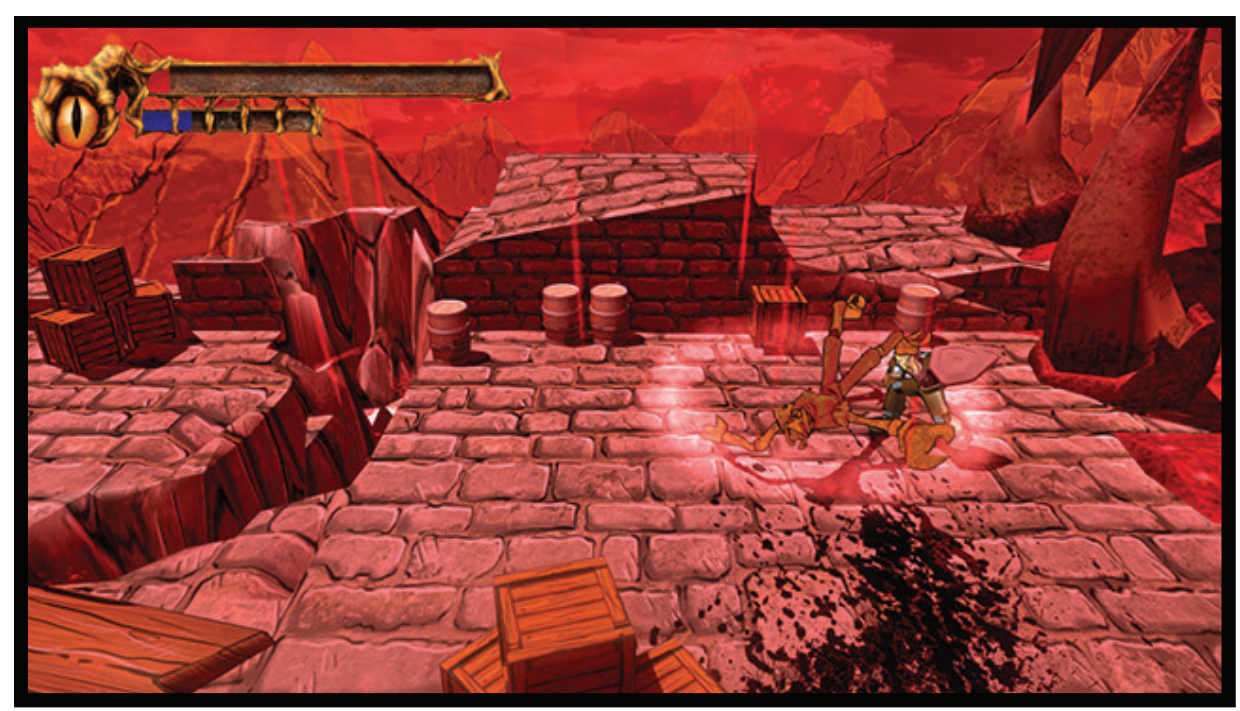


permitir alguns acabamentos, e, nesse caso, as imagens de tela poderiam receber pós-produção em um software de retoque de imagem.

Os alunos envolvidos nesta primeira etapa foram Willian Fardin, Cassio Souza, Dora Oliveira, Vinicius Cesari, Leonardo Paul, Giovanne Webster e Lucas Kollet, que trabalharam cerca de 20 horas semanais, sob supervisão geral do Prof. Me. Eduardo Müller.

0 início da pré-produção, que envolve a definição do escopo do projeto na primeira etapa, pesquisa, os character designs, concepts de cenários e prototipagem, teve uma duração de aproximadamente um mês (entre meados de setembro e outubro), e a etapa de produção e desenvolvimento do protótipo durou dois meses (da metade de outubro à metade de dezembro). Entre o período de aprovação das ideias, assim como as contrapropostas, tanto por parte da Editora quanto do Laboratório, foi cerca de mais um mês de prototipagem. 0 processo envolvendo as etapas de pré-produção, desenvolvimento e acabamento totalizou quatro meses.

Após concluído o protótipo de demonstração do Projeto Tormenta, passou-se à etapa de produção de um vídeo para ser utilizado na campanha de crowdfunding. A captação de imagens para 0 vídeo ocorreu em janeiro de 2013, contando com depoimentos dos envolvidos no projeto, bem como imagens de jogo, um making of de produção e 0 chamado para a participação como apoiador na campanha. A duração do vídeo, após editado, ficou em 5 minutos. Até este momento, nenhum valor havia sido estipulado para arrecadação do projeto.

\section{Planejamento de Campanha no Catarse}

One thing that's important to keep in mind is that every crowdfunding campaign is, at heart, essentially a consumer marketing effort. If people don't know about your project, there's no way they can contribute to it. ${ }^{8}$

Durante os meses de janeiro e fevereiro, ocorreu o planejamento da campanha de crowdfunding. Foi decidido que a plataforma do Catarse $^{9}$ seria a escolhida, em virtude da interface em língua portuguesa, da facilidade de pagamento em cartão de crédito nacional, da possibilidade de pagamento em boleto bancário e, principalmente, do menor valor de taxas a serem pagas no momento de recebimento do dinheiro, assim como o prazo de entrega do mesmo. 0 Catarse cobra

Propriedade Intelectual.

Tradução do trecho pelo autor: "Uma das coisas mais importantes para se manter em mente é que toda campanha de crowdfunding é, no fundo, essencialmente um esforço de marketing com o consumidor. Se as pessoas não souberem sobre 0 projeto, elas não têm como colaborar com ele" (STEINBERG; DEMARIA, 2012).

Disponível em: <http://catarse.me>. Acesso em: 01 mai. 2014. 
uma taxa de $13 \%$ sobre 0 valor final obtido em cada campanha (em que 7\% é do Catarse e 6\% é das operadoras de cartão de crédito), e, após a entrega do dinheiro, $7 \%$ recai como imposto sobre acumulação de capital, pelo governo, totalizando menos $20 \%$ do valor original apresentado na proposta de ideia ao público final.

A campanha seria toda voltada à internet, visto a velocidade de divulgação em mídias sociais, como Facebook e Twitter, sites especializados, e a facilidade da visualização imediata do projeto através de sua página oficial no Catarse, podendo o usuário de internet contribuir com o projeto em poucos cliques tão logo visse algum anúncio.

Estipulou-se que o período de duração da campanha seria de 40 dias. A opção pelo período ocorreu para que fosse uma campanha que tivesse longevidade, mas que não fosse longa demais, a fim de que não se corresse 0 risco de esquecimento por parte do público. Essas decisões foram tomadas com consultoria do próprio Catarse e, também, foram realizadas reuniões por Skype com a equipe mantenedora do site.

A definição de valor de projeto, não pelo cálculo dos custos, mas, sim, pelo valor que poderia ser atingido como uma meta viável de arrecadação, foi uma dúvida presente do início até o final de campanha, pois ele é o balizador da arrecadação. Calculou-se um valor necessário para a realização de um jogo pequeno, que envolvesse a contratação de três funcionários e dois estagiários por seis meses, e foram adicionados ao valor as taxas a serem pagas ao Catarse e os impostos. 0 cálculo final ficou em um valor aproximado de $\mathrm{R} \$ 60.000,00$.

Por orientação do Catarse, norteou-se 0 planejamento, tendo como princípio que o público tem noção dos valores de desenvolvimento de jogos digitais, ou, pelo menos, percepção relativa a outros produtos como livros, filmes e música, ou seja, ele teria noção de que esse valor proposto seria simbólico em comparação a jogos de grande orçamento, como os das séries Call of Duty e Grand Theft Auto, os quais lidam com orçamentos milionários.

\section{A Jambô Editora foi responsável por estipular} as recompensas a serem dadas aos apoiadores, baseando-se no estoque de livros e brindes já disponíveis na sede em Porto Alegre. Cada cota foi calculada de acordo com os valores dos produtos a serem dados como brindes, assim como 0 peso final dos mesmos, o que acarreta valores de correio diferentes. Entre os brindes, estavam disponíveis camisetas, pôsteres, livros, revistas em quadrinhos, livros-suplemento de RPG, cópias digitais e físicas do jogo, entre outros.

Além dos brindes baseados em produtos da Editora, algumas opções de brinde simbólico foram ofertadas, como, por exemplo, a possibilidade do apoiador inserir um personagem de criação própria dentro do jogo, contanto que ele apoiasse a campanha com um valor a partir de $\mathrm{R} \$ 800,00$. Os valores disponíveis para apoio nesta 
primeira etapa da campanha variavam entre $R \$ 25$

e $\mathrm{R} \$ 800$. À medida que a campanha se estendeu e houve 0 entendimento de que valores mais altos poderiam ser atrativos desde que sua premiação simbólica fosse perceptível, então, alterou-se 0 plano de recompensas.

0 Plano de Recompensas tornou-se fundamental para a execução de diversas das ações de divulgação e conversão de curtidores em apoiadores. A seguir, percebe-se que o plano se dividiu em recompensas tangíveis e intangíveis.
As recompensas estiveram presentes nas etapas de campanha. A campanha, de fato, se dividiu em três etapas:

Primeira Etapa, com duração de 7 dias e meta de $30 \%$ do valor final.

Segunda Etapa, com duração de 26 dias e meta de $50 \%$ do valor final.

Terceira Etapa, os 7 últimos dias da campanha e meta de $100 \%$ do valor final.

Quadro 1: Plano de Recompensas

\begin{tabular}{|c|c|c|c|}
\hline $\begin{array}{c}\text { Para (R\$) } \\
\text { ou mais }\end{array}$ & & Nome & Recompensas \\
\hline $\mathrm{R} \$ 10,00$ & 27 & KOBOLD & $\begin{array}{l}\text { - Seu nome nos agradecimentos. } \\
\text { - Diários de desenvolvimento do game, com conteúdo de jogo } \\
\text { para Tormenta RPG. } \\
\text { - Um “muito obrigado" dos criadores e fãs de Tormenta! }\end{array}$ \\
\hline $\mathrm{R} \$ 25,00$ & 168 & AVENTUREIRO & $\begin{array}{l}\text { - Seu nome nos agradecimentos. } \\
\text { - Diários de desenvolvimento do game, com conteúdo de } \\
\text { jogo para Tormenta RPG. } \\
\text { - Cópia digital do jogo. }\end{array}$ \\
\hline $\mathrm{R} \$ 30,00$ & 161 & CAÇADOR DE TESOUROS & $\begin{array}{l}\text { - Seu nome nos agradecimentos. } \\
\text { - Diários de desenvolvimento do game, com conteúdo de } \\
\text { jogo para Tormenta RPG. } \\
\text { - Cópia digital do jogo. } \\
\text { - Cupom na Loja Jambô no valor de } \mathrm{R} \$ 20,00 \text { (além do } \\
\text { game, você recebe de volta quase todo o seu dinheiro } \\
\text { em produtos!) }\end{array}$ \\
\hline $\mathrm{R} \$ 40,00$ & 86 & DEVOTO DO PANTEÃO & $\begin{array}{l}\text { - Seu nome nos agradecimentos. } \\
\text { - Diários de desenvolvimento do game, com conteúdo de } \\
\text { jogo para Tormenta RPG. } \\
\text { - Cópia digital do jogo. } \\
\text { - Cópia física do jogo, enviada para sua residência, } \\
\text { sem custo. }\end{array}$ \\
\hline $\mathrm{R} \$ 60,00$ & 24 & PORTADOR DO ESTANDARTE & $\begin{array}{l}\text { - Seu nome nos agradecimentos. } \\
\text { - Diários de desenvolvimento do game, com conteúdo de } \\
\text { jogo para Tormenta RPG. } \\
\text { - Cópia digital do jogo. } \\
\text { - Camiseta exclusiva de Tormenta. }\end{array}$ \\
\hline
\end{tabular}




\begin{tabular}{|c|c|c|c|}
\hline $\mathrm{R} \$ 60,00$ & 130 & CAVALEIRO DA LUZ & $\begin{array}{l}\text { - Seu nome nos agradecimentos. } \\
\text { - Diários de desenvolvimento do game, com conteúdo de } \\
\text { jogo para Tormenta RPG. } \\
\text { - Cópia digital do jogo. } \\
\text { - Cópia física do jogo, versão luxo (acompanha suplemento } \\
0 \text { Desafio dos Deuses para Tormenta RPG), enviada para } \\
\text { sua residência, sem custo. }\end{array}$ \\
\hline $\mathrm{R} \$ 80,00$ & 143 & MEMBRO DO PROTETORADO & $\begin{array}{l}\text { - Seu nome nos agradecimentos. } \\
\text { - Diários de desenvolvimento do game, com conteúdo de } \\
\text { jogo para Tormenta RPG. } \\
\text { - Cópia digital do jogo. } \\
\text { - Cópia física do jogo, versão luxo (acompanha suplemento } \\
0 \text { Desafio dos Deuses para Tormenta RPG) e autografada, } \\
\text { enviada para sua residência, sem custo. } \\
\text { - Cupom exclusivo de } 10 \% \text { de desconto para compras de } \\
\text { material de Tormenta na Loja Jambô. } \\
\text { - Marca-página exclusivo de Tormenta, com uma nova } \\
\text { habilidade para Tormenta RPG. } \\
\text { - Uma HQ, romance ou livro de RPG de Tormenta em } \\
\text { formato PDF à sua escolha. }\end{array}$ \\
\hline$R \$ 120,00$ & 65 & CAMPEÃO DE ARTON & $\begin{array}{l}\text { - Todas as recompensas do nível MEMBRO DO PROTETO- } \\
\text { RADO, mais: } \\
\text { - Camiseta exclusiva de Tormenta. } \\
\text { - Pôster do jogo autografado. }\end{array}$ \\
\hline $\mathrm{R} \$ 250,00$ & 9 & HERÓI ÉPICO & $\begin{array}{l}\text { - Todas as recompensas do nível MEMBRO DO PROTETO- } \\
\text { RADO, mais: } \\
\text { - Uma ilustração de um dos artistas da Jambô (mais } \\
\text { detalhes ao lado). }\end{array}$ \\
\hline$R \$ 250,00$ & 5 & ARQUIMAGO & $\begin{array}{l}\text { - Todas as recompensas do nível MEMBRO DO PROTETO- } \\
\text { RADO, mais: } \\
\text { - Conversa por Skype com autor de Tormenta ou desenvol- } \\
\text { vedor do jogo (mais detalhes ao lado). }\end{array}$ \\
\hline$R \$ 300,00$ & 1 & EXPLORADOR DA TORMENTA & $\begin{array}{l}\text { - Todas as recompensas do nível MEMBRO DO PROTETO- } \\
\text { RAD0, mais: } \\
\text { - Pacotão Tormenta Leitura (0 Inimigo do Mundo AUTO- } \\
\text { GRAFADO, DBride, Holy Avenger — Edição Definitiva Vol. 1, } \\
\text { Ledd Vol. 1). }\end{array}$ \\
\hline$R \$ 400,00$ & 5 & SEMIDEUS & $\begin{array}{l}\text { - Todas as recompensas do nível MEMBRO DO PROTETO- } \\
\text { RADO, mais: } \\
\text { - Participação figurativa de um personagem seu no game } \\
\text { (mais detalhes ao lado). }\end{array}$ \\
\hline $\mathrm{R} \$ 450,00$ & 0 & ADIVINHO & $\begin{array}{l}\text { - Todas as recompensas do nível MEMBRO DO PROTETO- } \\
\text { RAD0, mais: } \\
\text { - Hangout com Trio Clássico. }\end{array}$ \\
\hline $\mathrm{R} \$ 450,00$ & 0 & ORÁCULO & $\begin{array}{l}\text { - Todas as recompensas do nível MEMBRO DO PROTETO- } \\
\text { RAD0, mais: } \\
\text { - Hangout com Trio Ultimate. }\end{array}$ \\
\hline $\mathrm{R} \$ 500,00$ & 3 & CULTISTA DA TORMENTA & $\begin{array}{l}\text { - Todas as recompensas do nível MEMBRO DO PROTETO- } \\
\text { RADO, mais: } \\
\text { - Pacotão Tormenta Jogo (Tormenta RPG — Edição } \\
\text { Revisada, Tormenta RPG: Escudo do Mestre, Bestiário de } \\
\text { Arton, Expedição à Aliança Negra, Guerras Táuricas, Guia da } \\
\text { Trilogia, Manual do Arcano, Manual do Combate, Valkaria: } \\
\text { Cidade sob a Deusa). }\end{array}$ \\
\hline
\end{tabular}




\begin{tabular}{|c|c|c|c|}
\hline $\mathrm{R} \$ 600,00$ & 2 & LORDE DA TORMENTA & $\begin{array}{l}\text { - Todas as recompensas do nível MEMBRO DO PROTETO- } \\
\text { RAD0, mais: } \\
\text { - Pacotão Tormenta Leitura (0 Inimigo do Mundo AUTO- } \\
\text { GRAFADO, DBride, Holy Avenger — Edição Definitiva Vol. 1, } \\
\text { Ledd Vol. 1). } \\
\text { - Pacotão Tormenta Jogo (Tormenta RPG - Edição } \\
\text { Revisada, Tormenta RPG: Escudo do Mestre, Bestiário de } \\
\text { Arton, Expedição à Aliança Negra, Guerras Táuricas, Guia da } \\
\text { Trilogia, Manual do Arcano, Manual do Combate, Valkaria: } \\
\text { Cidade sob a Deusa). }\end{array}$ \\
\hline $\mathrm{R} \$ 600,00$ & 5 & DEUS MENOR & $\begin{array}{l}\text { - Todas as recompensas do nível MEMBRO DO PROTETO- } \\
\text { RADO, mais: } \\
\text { - Participação de um personagem seu no game (mais } \\
\text { detalhes ao lado). }\end{array}$ \\
\hline $\mathrm{R} \$ 800,00$ & 5 & DEUS MAIOR & $\begin{array}{l}\text { - Todas as recompensas do nível MEMBRO DO PROTETO- } \\
\text { RADO, mais: } \\
\text { - Seu personagem torna-se uma das lendas de Arton, } \\
\text { entrando OFICIALMENTE no cenário de Tormenta. }\end{array}$ \\
\hline $\mathrm{R} \$ 1.200,00$ & 2 & A PENA VENCE A ESPADA & $\begin{array}{l}\text { - Todas as recompensas do nível MEMBRO DO PROTETO- } \\
\text { RAD0, mais: } \\
\text { - Conto de Leonel Caldela sobre seu personagem. }\end{array}$ \\
\hline $\mathrm{R} \$ 1.500,00$ & 2 & SAGA DE HERÓIS & $\begin{array}{l}\text { - Todas as recompensas do nível MEMBRO DO PROTETO- } \\
\text { RADO, mais: } \\
\text { - HQ com roteiro de Marcelo Cassaro e arte de Rafael } \\
\text { Françoi sobre seu personagem. }\end{array}$ \\
\hline $\mathrm{R} \$ 1.750,00$ & 0 & AUDIÊNCIA NO SENADO & $\begin{array}{l}\text { - Todas as recompensas do nível MEMBRO DO PROTETO- } \\
\text { RAD0, mais: } \\
\text { - Sessão de RPG com Trio Ultimate. }\end{array}$ \\
\hline $\mathrm{R} \$ 1.750,00$ & 0 & $\begin{array}{c}\text { AUDIÊNCIA NO } \\
\text { PALÁCIO IMPERIAL }\end{array}$ & $\begin{array}{l}\text { - Todas as recompensas do nível MEMBRO DO PROTETO- } \\
\text { RAD0, mais: } \\
\text { - Sessão de RPG com Trio Clássico. }\end{array}$ \\
\hline $\mathrm{R} \$ 2.000,00$ & 3 & ENTIDADE CÓSMICA & $\begin{array}{l}\text { - Todas as recompensas do nível DEUS MAIOR, mais: } \\
\text { - Seu personagem na capa do acessório Tormenta: } 0 \\
\text { Desafio dos Deuses. }\end{array}$ \\
\hline
\end{tabular}

Fonte: Os autores

Considerou-se que, no início de campanha, o projeto seria visto como novidade ao público, e isso poderia colaborar de forma efetiva com o projeto durante a primeira semana, principalmente pela divulgação em sites especializados, os quais estavam contemplados em serem os primeiros a receber as informações sobre o lançamento do projeto.

Na segunda etapa, o projeto não possui o caráter de novidade, sendo natural uma curva decrescente nas contribuições, estabelecendo-se assim uma meta menor, de 20\%. Como ações específicas de divulgação, priorizaram-se entrevistas com os criadores e a disponibilização de mais detalhes do projeto, a fim de gerar comentários constantes por parte do público.

Na fase final da campanha, trabalhou-se com novos releases e a colaboração efetiva dos fãs na divulgação em redes sociais, considerando que 
esses entendessem que não alcançar a meta era não ter o jogo pelo qual almejavam. Com o prazo da campanha se encerrando, esperava-se uma maior quantidade de colaboradores aderindo ao projeto, tendo em vista uma condição humana natural de deixar tarefas para a última hora e, possivelmente, atingir um valor maior do que o esperado.

\section{Desenvolvimento da Campanha}

A Campanha de Arrecadação para 0 Tormenta ocorreu durante 40 dias e, após esse período, foi realizada uma análise das ações, 0 que permitiu que fossem vislumbrados três momentos distintos de comunicação.

\section{A. Primeira Etapa}

As primeiras ações foram planejadas antes do dia 1 de campanha, para que pudesse ocorrer desde 0 exato momento em que 0 jogo entrasse para os projetos do Catarse. Estabeleceu-se uma lista de sites específicos de jogos (100), entre blogs, vlogs, fanpages e portais. Foi encaminhado um Press Release com textos sobre o projeto, sobre o jogo e imagens de alta resolução para divulgação. Em torno de 60 sites utilizaram o material para divulgar informações sobre o projeto. Dos restantes, alguns não responderam às mensagens e outros cobravam pela divulgação de conteúdo.

Ao mesmo tempo em que as informações estavam aparecendo nos sites, obteve-se uma primeira onda de colaborações a partir de uma lista prévia realizada de contatos com pessoas relevantes do mercado de RPG, Quadrinhos e Jogos. Isso para que outros colaboradores pudessem verificar que pessoas já haviam colaborado, e que algumas dessas eram relevantes à indústria.

Com as ações ocorridas no dia 1 de campanha (05/03/2013), foi possível verificar uma sequência de outros sites e colaboradores que se engajaram em repassar as informações e buscar novos colaboradores de forma espontânea. No início, a recepção do projeto por parte do público foi positiva, em que os fãs de Tormenta passaram a divulgar a ideia e a colaborar. Nos dois primeiros dias, o montante atingido foi de $R \$ 6.500,00$, e na primeira semana, $\mathrm{R} \$ 17.500,00$, próximo à meta de $30 \%$ estabelecida.

\section{B. Segunda Etapa}

Nesta etapa era previsto que a explosão inicial de colaboração diminuísse, portanto, elaborouse uma estratégia de participação em canais, aceitando convites vindos das primeiras semanas como participação em podcasts, entrevistas para blogs/revistas e respondendo às dúvidas do público com relação ao projeto.

Além das ações de relações públicas, estabeleceuse a operação de atualização diária da página de projeto no Catarse; a criação de uma história em quadrinhos de 4 páginas; a inserção de novas categorias de recompensa, contendo brindes 
diferenciados; e a divulgação de um novo vídeo, que mostrou uma sessão de game test, com a presença de desenvolvedores de games e fãs de Tormenta influentes do público de RPG, atestando a qualidade do jogo.

Este período se estabeleceu como crítico durante a campanha, pois as contribuições diárias estavam caindo, sendo que a menor diária foi de apenas R \$30,00 em um dos dias. No final desta etapa, com 35 dias de campanha, atingiu-se 0 valor de $\mathrm{R} \$ 34.350,00$ (Fig. 2), quantia compatível com 0 planejamento inicial, porém, mesmo assim, foram geradas dúvidas sobre o cumprimento da meta de $\mathrm{R} \$ 60.000,00$, visto a atitude de parte do público que reagiu negativamente ao projeto.

Esta porcentagem do público foi batizada de haters $^{10}$, composta, teoricamente, por pessoas que não gostavam do projeto por razões diversas, mas verificou-se, pela coleta de comentários, que um motivo em particular demonstrou-se recorrente:

0 fato de 0 jogo ser produzido por uma equipe brasileira, tornando isso motivo de deboche em fóruns de fãs de games (Fig.3).

\section{Terceira Etapa}

Na etapa final, avaliou-se que este era o momento de investir os esforços de divulgação em todos os meios disponíveis, isso devido ao crescimento dos haters, e com o discurso de que, colaborando com o projeto, a pessoa não estaria colaborando apenas com o projeto Tormenta, mas com toda a indústria nacional de games. Enviou-se aos meios um novo Press Release, enfatizando 0 caráter de urgência das colaborações, dado o prazo de última semana de campanha. Assim, novas recompensas foram adicionadas e uma nova imagem de jogo foi divulgada, gerando novamente motivo para os comentários e engajamento dos fãs na campanha. Os integrantes da equipe de criação participaram em palestras sobre o projeto em

Figura 2: Indo para Terceira Etapa

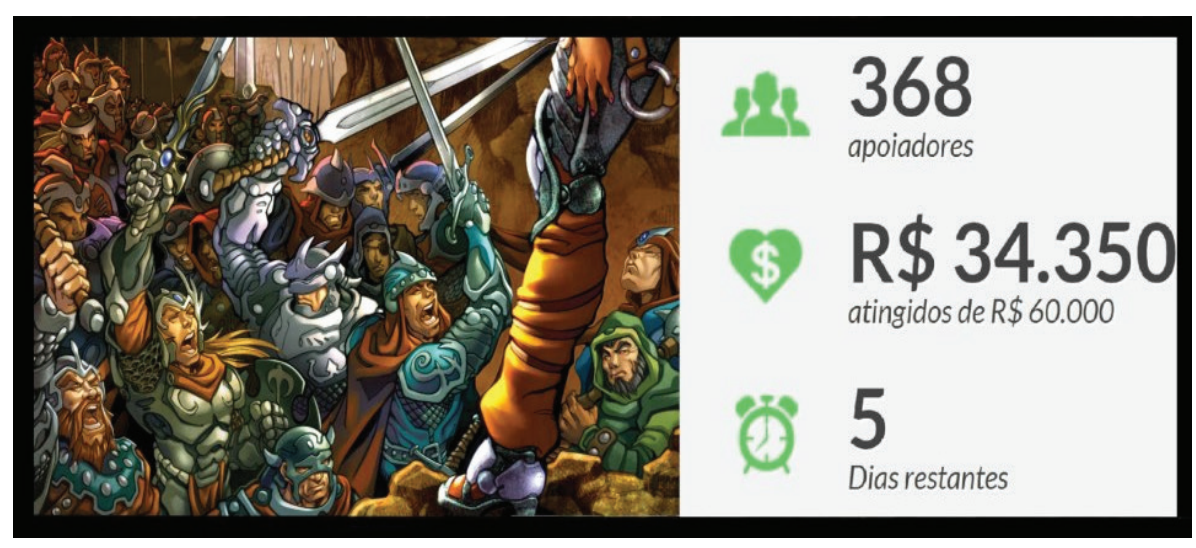

Fonte: 0s autores 
Figura 3: Comentários dos Haters

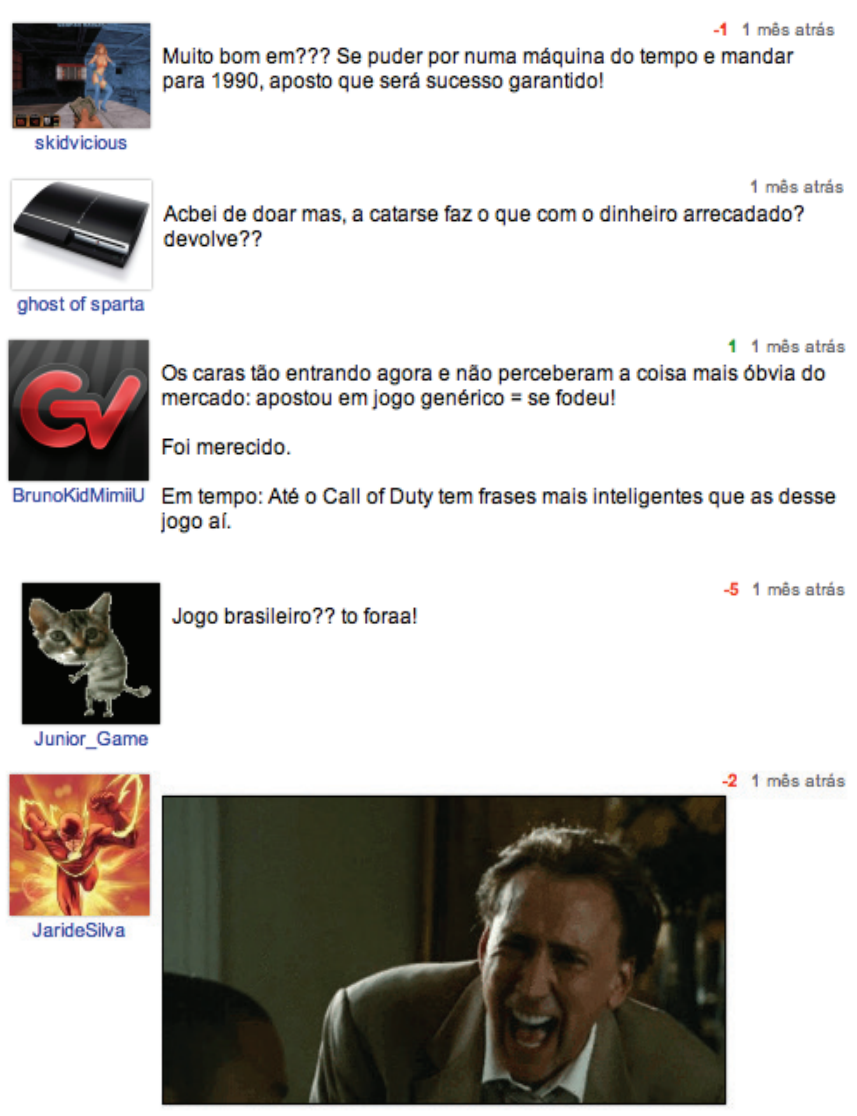

Jogo Brasileiro ê? KKKKKKK

Fonte: Os autores

eventos de cultura pop, assim como de Hangouts

pela internet, atuando diretamente com o público. A

meta de $\mathrm{R} \$ 60.000,00$ (Fig. 4) foi alcançada faltando

cerca de 24 horas para o término do prazo, e as

contribuições continuaram aparecendo, chegando a

um total de $\mathrm{R} \$ 74.575,00$ em seu encerramento.

\section{Considerações Finais}

A campanha obteve 864 colaboradores, que depositaram a quantia total de $\mathrm{R} \$ 74.575,00$.

A página do projeto alcançou mais de 200.000 visualizações no Catarse, 8.000 likes no
Facebook e 1800 tweets no Twitter, contando com aproximadamente 27.600 visualizações do vídeo principal de divulgação. Para cada 100 visualizações da página no Catarse, 10,6 pessoas assistiram ao vídeo, e 3,1 pessoas se tornaram colaboradoras. "An unexpected benefit of crowdfunding campaigns is that you will often receive very useful advice - and even tangible offers of assistance - from backers, who, after all, want you to succeed and will do everything they can to help you get there". ${ }^{11}$

Consideraram-se decisivos para a campanha 0 apoio dos sites Jovem Nerd, NerdMaldito, 


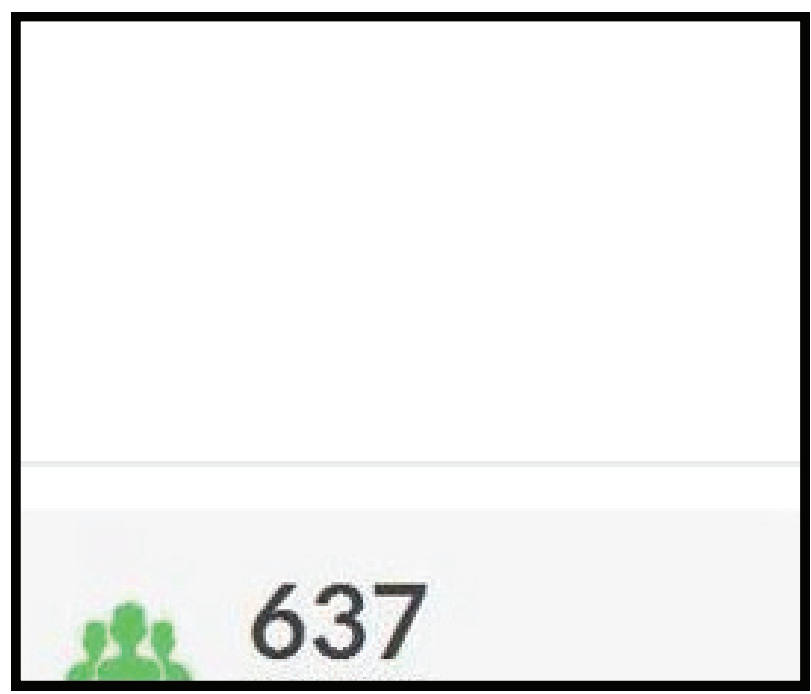

Fonte: 0s autores

Omelete, N-pix, ditopelomaldito e Kotaku, e o caráter emocional que foi dado ao projeto por parte dos fãs, engajados nas tarefas de divulgação em sites e no Facebook, assim como de desenvolvedores de games. De certa maneira, a polêmica da equipe brasileira foi positiva, pois contribuiu para a divulgação do projeto e trouxe os colaboradores mais próximos.

No fim do processo, chegou-se a duas conclusões: primeiro, o grande público consumidor de games não tem a exata noção de quanto custa a produção de um jogo, devido às críticas recebidas, em que boa parte esperava um jogo mais elaborado, no mesmo nível dos jogos de grande orçamento encontrados no mercado mundial. Segundo: é preciso planejar como proceder ao receber likes do Facebook e tweets do Twitter. Uma quantidade considerável de pessoas simpatiza com 0 projeto via rede social, compartilha, mas não apoia financeiramente o projeto. É fundamental pensar em estratégias que tornem a participação deste público em algo tangível, possivelmente com promoções ou parcerias.

Percebe-se que o modelo de crowdfunding é utilizado por diversos projetos de jogos digitais (STEINBERG; DEMARIA, 2012). Esse modelo não é o único, contudo, na atual situação do cenário econômico e mercadológico brasileiro, se apresenta como uma alternativa viável para alavancar recursos financeiros equivalentes a um angel investor, ou um capital de risco pequeno (venture 
capital). Segundo Gordon (2009), os modelos de negócios não são designados de acordo com um determinado tipo de produto; eles são modelados e aparecem conforme as necessidades de consumo e a viabilidade financeira dos projetos, produtos e serviços que devem ser entregues aos compradores.

0 jogo Tormenta é um projeto que apresenta potencial científico de acompanhamento e registro de suas etapas. Atualmente, já se iniciaram os processos de desenvolvimento, e todas as etapas estão sendo coletadas para gerar novos ensaios que demonstrem a gestação dos recursos adquiridos nesse processo de campanha, dentre outras situações comunicacionais que ocorrem, como lidar com os apoiadores e os haters nessa próxima etapa de projeto.

\section{Referências}

GORDON, Michael E. Trump University

Entrepreneurship 101: How to Turn Your Idea into a Money Machine. New Jersey: Wiley, 2009.

HOWKINS, John. The Creative Economy: How People Make Money from Ideas. Kindle Edition ed. London: Penguin Books, 2007.

NEWMAN, James. Videogames. 1st ed. London: Routledge, 2004.

NEWZ00. Disponível em: < http://www.newzoo.com/ press-releases/global-games-market-grows-to-861bn-in-2016/attachment/newzoo_global_games_ market_2012-2016_v1_tn/>. Acesso em: 01 ago. 2014.

STEINBERG, Scott; DEMARIA, Rusel. The

Crowdfunding Bible: How to Raise Money for any StartUp, Video Game or Project. Kindle Edition ed.:

Read.Me, 2012. 


\section{La tormenta de un crowdfunding} de juego de Brasil

\section{Resumen}

Abstract

Financing models and incentive for game projects in Brazil are being further developed and applied in order to realize how the production process fits with project management and fundraising. This article demonstrates the process of planning and executing a crowdfunding campaign for the game "Tormenta: Challenges of the Gods" realized by University Feevale of Novo Hamburgo, Rio Grande do Sul, and Jambo Editorial Publisher that holds the intellectual property of Tormenta RPG System. This project raised the largest amount of a Brazilian Digital Game Project until now, more than $\mathrm{R} \$ 70.000,00$ real, in a National Crowdfunding System. The analysis considers the nature of the projects in the Creative Economy, the process of Communication Campaign and metrics attained in the moments of ad actions accomplishments.

\section{Keywords}

Creative Industry. Business Models. Digital Games.
Los modelos de financiación y la financiación de proyectos de juegos en Brasil se están desarrollando más y aplicarse con el fin de darse cuenta de cómo el proceso de producción se ajusta a la gestión de proyectos y recaudación de fondos. Este artículo muestra el proceso de planificación y ejecución de la campaña crowdfunding del juego "Tormenta - los retos de los Dioses", que se celebró entre Universidad Feevale de Novo Hamburgo, Río Grande do Sul, y el Jambô Editoria, propietaria del sistema de propiedad intelectual RPG Tormenta. Este proyecto ha recaudado más grande de dinero de juegos digitales de Brasil hasta el momento, más de 70.000 reales en un sistema nacional de Crowdfunding. El análisis considera la naturaleza de los proyectos en la economía creativa, el proceso de la Campaña de Comunicación y métrica alcanzado en tiempos de logros de las acciones.

\section{Palabras-Clave}

Industrias Creativas. Modelos de negocio. Juegos digitales. 


\section{Expediente}

A revista E-Compós é a publicação científica em formato eletrônico da Associação Nacional dos Programas de Pós-Graduação em Comunicação (Compós). Lançada em 2004, tem como principal finalidade difundir a produção acadêmica de pesquisadores da área de Comunicação, inseridos em instituições do Brasil e do exterior.

\section{E-COMPÓS I www.e-compos.org.br I E-ISSN 1808-2599}

Revista da Associação Nacional dos Programas

de Pós-Graduação em Comunicacão.

Brasília, v.17, n.3, set./dez. 2014

A identificação das edições, a partir de 2008

passa a ser volume anual com três números.

\section{CONSELHO EDITORIAL}

Afonso Albuquerque, Universidade Federal Fluminense, Brasil Alberto Carlos Augusto Klein, Universidade Estadual de Londrina, Brasil Alex Fernando Teixeira Primo, Universidade Federal do Rio Grande do Sul, Brasil Rio Grande do Sul, Brasi

Ana Gruszynski, Universidade Federal do Rio Grande do Sul, Brasil Ana Silvia Lopes Davi Médola, Universidade Estadual Paulista, Brasil André Luiz Martins Lemos, Universidade Federal da Bahia, Brasi Ângela Freire Prysthon, Universidade Federal de Pernambuco, Brasil Antônio Fausto Neto, Universidade do Vale do Rio dos Sinos, Brasil Antonio Carlos Hohlfeldt, Pontifícia Universidade Católica do Rio Grande do Sul, Brasil Antonio Roberto Chiachiri Filho, Faculdade Cásper Líbero, Brasi Arlindo Ribeiro Machado, Universidade de São Paulo, Brasil Arthur Autran Franco de Sá Neto, Universidade Federal de São Carlos, Brasil Benjamim Picado, Universidade Federal Fluminense, Brasil César Geraldo Guimarães, Universidade Federal de Minas Gerais, Brasil Cristiane Freitas Gutfreind, Pontifícia Universidade Católica do Rio Grande do Sul, Brasil Denilson Lopes, Universidade Federal do Rio de Janeiro, Brasil Denize Correa Araujo, Universidade Tuiuti do Paraná, Brasil Edilson Cazeloto, Universidade Paulista, Brasil

Eduardo Vicente, Universidade de São Paulo, Brasil

Eneus Trindade, Universidade de São Paulo, Brasil

Erick Felinto de Oliveira, Universidade do Estado do Rio de Janeiro, Brasil Florence Dravet, Universidade Católica de Brasilia, Brasil

Gelson Santana, Universidade Anhembi/Morumbi, Brasi Gilson Vieira Monteiro, Universidade Federal do Amazonas, Brasil Gislene da Silva, Universidade Federal de Santa Catarina, Brasil Guillermo Orozco Gómez, Universidad de Guadalajara, México Gustavo Daudt Fischer, Universidade do Vale do Rio dos Sinos, Brasil Hector Ospina, Universidad de Manizales, Colômbia Herom Vargas, Universidade Municipal de São Caetano do Sul, Brasil leda Tucherman, Universidade Federal do Rio de Janeiro, Brasil Inês Vitorino, Universidade Federal do Ceará, Brasil Janice Caiafa, Universidade Federal do Rio de Janeiro, Brasil Jay David Bolter, Georgia Institute of Technology, Estados Unidos Jeder Silveira Janotti Junior, Universidade Federal de Pernambuco, Brasi João Freire Filho, Universidade Federal do Rio de Janeiro, Brasil John DH Downing, University of Texas at Austin, Estados Unidos Ana Carolina Damboriarena Escosteguy, Pontifícia Universidade Católica do

José Afonso da Silva Junior, Universidade Federal de Pernambuco, Brasil José Carlos Rodrigues, Pontifícia Universidade Católica do Rio de Janeiro, Brasil José Luiz Aidar Prado, Pontifícia Universidade Católica de São Paulo, Brasil José Luiz Warren Jardim Gomes Braga, Universidade do Vale do Rio dos Sinos, Brasil Juremir Machado da Silva, Pontifícia Universidade Católica do Rio Grande do Sul, Brasil Laan Mendes Barros, Universidade Metodista de São Paulo, Brasi Lance Strate, Fordham University, USA, Estados Unidos Lorraine Leu, University of Bristol, Grã-Bretanha Lucia Leão, Pontifícia Universidade Católica de São Paulo, Brasil Luciana Panke, Universidade Federal do Paraná, Brasil Luiz Claudio Martino, Universidade de Brasília, Brasil Malena Segura Contrera, Universidade Paulista, Brasil Márcio de Vasconcellos Serelle, Pontifícia Universidade Católica de Minas Gerais, Brasil Maria Aparecida Baccega, Universidade de São Paulo e Escola Superior de Propaganda e Marketing, Brasi Maria das Graças Pinto Coelho, Universidade Federal do Rio Grande do Norte, Brasil Maria Immacolata Vassallo de Lopes, Universidade de São Paulo, Brasil Maria Luiza Martins de Mendonça, Universidade Federal de Goiás, Brasil Mauro de Souza Ventura, Universidade Estadual Paulista, Brasil Mauro Pereira Porto, Tulane University, Estados Unidos Nilda Aparecida Jacks, Universidade Federal do Rio Grande do Sul, Brasil Paulo Roberto Gibaldi Vaz, Universidade Federal do Rio de Janeiro, Brasil Potiguara Mendes Silveira Jr, Universidade Federal de Juiz de Fora, Brasil Renato Cordeiro Gomes, Pontifícia Universidade Católica do Rio de Janeiro, Brasil Robert K Logan, University of Toronto, Canadá

Ronaldo George Helal, Universidade do Estado do Rio de Janeiro, Brasil Rosana de Lima Soares, Universidade de São Paulo, Brasi Rose Melo Rocha, Escola Superior de Propaganda e Marketing, Brasil Rossana Reguillo, Instituto de Estudos Superiores do Ocidente, México Rousiley Celi Moreira Maia, Universidade Federal de Minas Gerais, Brasi Sebastião Carlos de Morais Squirra, Universidade Metodista de São Paulo, Brasil Sebastião Guilherme Albano da Costa, Universidade Federal do Rio Grande do Norte, Brasil

Simone Maria Andrade Pereira de Sá, Universidade Federal Fluminense, Brasi Suzete Venturelli, Universidade de Brasília, Brasil

Tiago Quiroga Fausto Neto, Universidade de Brasília, Brasil

Valerio Fuenzalida Fernández, Puc-Chile, Chile

Veneza Mayora Ronsini, Universidade Federal de Santa Maria, Brasi Vera Regina Veiga França, Universidade Federal de Minas Gerais, Brasil

\section{COMISSÃO EDITORIAL}

Cristiane Freitas Gutfreind I Pontifícia Universidade Católica do Rio Grande do Sul, Brasil Irene Machado I Universidade de São Paulo, Brasil

Jorge Cardoso Filho I Universidade Federal do Recôncavo da Bahia, Brasil Universidade Federal da Bahia, Brasil

CONSULTORES AD HOC

Adriana Amaral, Universidade do Vale do Rio dos Sinos, Brasil

Alexandre Rocha da Silva, Universidade Federal do Rio Grande do Sul, Brasi

Arthur Ituassu, Pontifícia Universidade Católica do Rio de Janeiro, Brasil

Bruno Souza Leal, Universidade Federal de Minas Gerais, Brasil

Elizabeth Bastos Duarte, Universidade Federal de Santa Maria, Brasil

Francisco Paulo Jamil Marques, Universidade Federal do Ceará, Brasi

Maurício Lissovsky, Universidade Federal do Rio de Janeiro, Brasil

Suzana Kilpp, Universidade do Vale do Rio dos Sinos, Brasil

Vander Casaqui, Escola Superior de Propaganda e Marketing, Brasi

EDIÇ̃̃O DE TEXTO E RESUMOS I Press Revisão

SECRETÁRIA EXECUTIVA I Helena Stigger

EDITORAÇÃo ELETRÔNICA I Roka Estúdio
COMPÓS I www.compos.org.br

Associação Nacional dos Programas de Pós-Graduação em Comunicação

Presidente

Eduardo Morettin

Universidade de São Paulo, Brasil

eduardomorettin@usp.br

Vice-presidente

Inês Vitorino

Universidade Federal do Ceará, Brasil

ines@ufc.br

Secretária-Geral

Gislene da Silva

Universidade Federal de Santa Catarina, Brasil

gislenedasilva@gmail.com 